\title{
The Production of Communication Signals at the Air-Water and Water-Substrate Boundaries
}

\author{
Sean C. Lema and John T. Kelly
}

\begin{abstract}
The 2 interfaces of the aquatic environment, the boundary between air-water and water-substrate, have distinctive physical characteristics that facilitate the production of communication signals. Recent evidence suggests that animals living on or near these boundaries use the interface to generate signals in 2 ways: (a) by producing a signal that propagates along the interface or (b) by producing a signal at the interface that is transmitted and detected within 1 of the component media. By examining the diversity of behaviors used to produce signals at these boundaries, the authors illustrate how human perception of these environments may cause researchers to incorrectly assume the environmental context of signalgenerating behaviors and overlook modalities of communication pertinent to the animal.
\end{abstract}

Animals inhabit diverse environments and use a variety of mechanisms to produce signals for communication. Naturally, the modalities of communication that have received the most study are assumed to be the types of signals that are the most salient to the animal in its environment. Each animal, however, occupies its own sensory world, or Umwelt. Each animal perceives a different set of sensory cues and responds to these cues in a different way (Von Uexküll, 1934/1957). The Umwelt has become such a fundamental tenet of the study of animal behavior that it is rarely considered directly. Yet, when the sensory modalities that are commonly recognized in communication are examined, it is apparent that in some cases researchers may have lost sight of Von Uexküll's admonition. The understanding of the sensory modalities of communication, and indeed, the focus of much previous research, shows a bias from how researchers perceive an animal's environment. This bias is particularly evident in the understanding of communication for animals that inhabit environments with unfamiliar physical properties.

For instance, the physical properties of the aquatic environment make the characteristics of signal transmission distinctive from those of a terrestrial environment. Light energy is rapidly absorbed by even the clearest water, limiting light transmission to the few hundred meters at the top of the water column, and visual communication may play a secondary role in many aquatic species. The density and relative incompressibility of water allows acoustic communication over long distances while making the localization of sound sources difficult. As terrestrial creatures, the physical properties of the aquatic environment make it difficult for us as humans to conceive of communication in an aquatic medium. This may cause researchers to overlook the existence or importance of alternate sensory modalities of communication by aquatic animals.

Recent evidence has shown that many animals that live on or near an interface such as the boundary between air and water or between water and substrate may have evolved to take advantage of these boundaries for communication. These interfaces may be used in at least two distinct ways: (a) animals may use the interface as a channel by generating and receiving signals at the interface or (b) animals may use the interface to generate a signal that is transmitted and detected within one of the component media. The goal of this article is to examine the diversity of behavioral mechanisms that organisms use to produce signals at the interfaces of the aquatic environment. Many of the mechanisms used for producing signals at an interface involve behaviors that are already recognized to play a role in the production of signals in other modalities. Because of biases, however, researchers can overlook the use of signals in additional modalities and misjudge how the environmental context of a behavior influences the relative importance of those modalities. By examining a diversity of taxa, we illustrate how researchers' perceptual biases as humans may skew the understanding of the behavioral mechanisms used to produce signals and cause researchers to disregard modalities of communication that are salient to animals at the interfaces of the aquatic environment.

\section{The Interface as a Channel for Communication}

The boundary between air and water or between water and substrate is defined by an abrupt change in molecular density that creates an asymmetry of molecular forces at the interface. This boundary may serve as a channel for the transmission of communication signals. A disruption of the intermolecular forces at a source location on the interface can generate a vibrational wave that propagates horizontally in all directions away from the source. At the air-water interface, a disturbance generates surface waves. In contrast, vibrational signals are transmitted as Rayleigh waves at the water-substrate interface. This situation is comparable with 
the transmission of vibratory signals at the air-substrate interface (Arnason, Hart, \& O’Connell-Rodwell, 2002). The transmission distance of a water-substrate vibrational signal depends on the intensity and attenuation rate of the signal as well as the composition of the substrate.

\section{Surface Wave Communication}

Surface waves at the air-water interface are generated by wind, water currents, falling leaves, or movements of animals. It has long been recognized that many aquatic animals use surface waves to locate prey and to avoid predators (reviewed in Bleckmann, 1994). However, an animal that uses surface waves to locate a prey item must differentiate surface waves that indicate the presence of a prey item from waves that are generated by wind and other sources of background noise. Bleckmann (1985) showed that the semiaquatic fishing spider (Dolomedes triton) discriminates between surface wave stimuli from struggling prey and abiotic sources on the basis of the duration and frequency of wave generation and the regularity of the stimulus in frequency and amplitude. Signals generated by struggling prey items are typically of high frequency, long duration, low amplitude, and irregular time course. In contrast, abiotic noises are generally low frequency, short duration, and high amplitude. If animals can distinguish between surface waves generated by prey and abiotic sources, then animals may also be able to recognize waves generated by conspecifics for communication.

At present, there is a wide diversity of taxa including amphibians, surface-oriented fishes, insects, and arachnids that are recognized to use surface waves for communication (see Table 1 ; for a review of insects, see Wilcox, 1995). For instance, both males and females of the water strider (Rhagadotarsus anomalus) communicate by surface waves during mating (Wilcox, 1972). Males produce multiple types of signals either while stationary on the water surface or while gripping a fixed or floating object such as a branch or stick. These objects are used as calling sites by males and later serve as oviposition sites for females. Calling signals are characterized by sequences of high-amplitude waves that are pro- duced by horizontal strokes of the midlegs, whereas courtship signals are characterized by low-amplitude waves produced by vertical oscillation of the forelegs. Females produce only lowamplitude courtship signals. Using artificially generated wave stimuli, Wilcox (1972) showed that females exhibit a vibrotaxis toward calling signals and even oviposit in response to wave stimuli alone.

Similarly, parental males of the fighting fish (Betta splendens) produce surface waves to communicate with newly hatched offspring (Kühme, 1961). In the days following hatching, juvenile Siamese fighting fish move about the environment but usually remain in contact with the water surface. In response to a disturbance, the parental male positions himself at the air-water interface and rapidly beats his pectoral fins to generate surface waves. The juveniles detect these surface waves through neuromast cells on the head and respond by swimming toward the source of the surface waves. As the juveniles approach the wave source, the parental male collects the juveniles in his mouth cavity for protection (Kühme, 1961).

\section{Vibratory Communication Through the Substrate}

Many benthic fish produce acoustic sounds during courtship and agonistic behaviors (e.g., Tavolga, 1958). For instance, males of the river bullhead (Cottus gobio) are known to produce acoustic sounds of $50-500 \mathrm{~Hz}$ (Ladich, 1989). River bullhead produce these sounds during a motor pattern that has been described as a head nod. A head nod is performed while the fish is prone on the substrate with its pelvic fins extended and is characterized by a swift adduction of the pectoral girdle relative to the cranium (Ladich, 1989).

The mottled sculpin (Cottus bairdi) also performs head nods during agonistic interactions (Savage, 1963). Although there may be an acoustic signal produced by this behavior, the physiology and ecology of this species suggest an additional role for this behavior in communication. Because of the similar density of a fish's body and the surrounding media, hearing in fish is constrained to receiving near-field particle motion unless some struc-

Table 1

Methods of Signal Production and Detection in Taxa That Communicate Through Water Surface Waves

\begin{tabular}{|c|c|c|c|}
\hline Taxon & Method of surface wave production & $\begin{array}{l}\text { Sensory system for surface } \\
\text { wave reception }\end{array}$ & Reference \\
\hline \multicolumn{4}{|l|}{ Amphibians } \\
\hline $\begin{array}{l}\text { Yellow-bellied toad (Bombina } \\
\text { variegata) }\end{array}$ & Kicking of hind legs & Epidermal neuromasts & Seidel (1999) \\
\hline $\begin{array}{l}\text { Fire-bellied toad (Bombina } \\
\text { bombina) }\end{array}$ & $\begin{array}{l}\text { Gular motions during calling; kicking } \\
\text { of hind legs; swimming }\end{array}$ & Epidermal neuromasts & Walkowiak \& Münz (1985) \\
\hline \multicolumn{4}{|l|}{ Fishes } \\
\hline $\begin{array}{l}\text { Siamese fighting fish (Betta } \\
\text { splendens) }\end{array}$ & Pectoral fin movement & Head neuromasts & Kühme (1961) \\
\hline \multicolumn{4}{|l|}{ Insects } \\
\hline $\begin{array}{c}\text { Water strider (Rhagadotarsus } \\
\text { anomalus) }\end{array}$ & Midleg movement; foreleg movement & $\begin{array}{l}\text { Tibiotarsal receptors; sensory hairs } \\
\text { on legs }\end{array}$ & Wilcox (1972) \\
\hline Giant water bug (Abedus indentatus) & $\begin{array}{l}\text { Body pumping while anchored to } \\
\text { object }\end{array}$ & Hair sensillae at joints & Kraus (1989) \\
\hline \multicolumn{4}{|l|}{ Arachnids } \\
\hline Fishing spider (Dolomedes triton) & $\begin{array}{l}\text { Leg drumming (males); pedipalp } \\
\text { motion (females) }\end{array}$ & $\begin{array}{l}\text { Slit sense organs; leg joint } \\
\text { receptors }\end{array}$ & Roland \& Rover (1983) \\
\hline
\end{tabular}


ture couples the far-field pressure wave to the fish's inner ear (reviewed in Popper \& Fay, 1993). This coupling is usually performed by the swimbladder. However, mottled sculpin, like many benthic fish, lack a swimbladder and may be unable to detect the far-field, acoustic signals generated by a head nod. Furthermore, male sculpins often excavate nests for breeding in the riffle areas of freshwater streams. Background acoustic noise in these habitats is expected to be high because of the water turbulence and bubble formation in the stream, thus limiting the effectiveness of far-field, acoustic signals in communication (Whang \& Janssen, 1994). Although sculpins may be limited in their ability to detect acoustic signals, they possess ample structures for detecting the particle displacement typical of seismic signals. Furthermore, the seismic channel in rivers appears to be relatively quiet, and vibratory signals may travel further than acoustic signals because of a lower attenuation rate (Whang \& Janssen, 1994).

Mottled sculpins consume benthic prey including oligochaetes, amphipods, and midge larvae (Hoekstra \& Janssen, 1985). Janssen (1990) showed that mottled sculpins can detect seismic cues produced by live prey and can localize the source of these vibrational stimuli using their lateral line organ. On the advent of a vibrational stimulus, sculpins orient in the direction of the stimulus source. They then make a series of short swimming hops toward the vibrational source while stopping briefly between each hop and placing their lower mandible to the substrate (Janssen, 1990). Pharmacological inhibition of the lateral line neuromasts prevented the sculpins from localizing the source of the vibrational stimulus, though it did not prevent the initial detection of the stimulus. On the basis of this evidence, Janssen (1990) suggested that substrate vibrations might be detected in part through the inner ear but that the lateral line is necessary for localization of the source.

To extend Janssen's (1990) finding that sculpin can detect seismic stimuli, Whang and Janssen (1994) explored whether sculpin can also produce seismic signals. The prone position and extended pelvic fins observed during the head-nod behavior suggests that some energy from the behavior may be transmitted through the substrate. Whang and Janssen recorded and characterized three types of seismic signals produced by the mottled sculpin: (a) knocks, which are produced by a head nod and the swift expansion of the buccal cavity; (b) head slaps, which are forward thrusts of the body followed by a rapid slap of the head into the substrate; and (c) drumroll, which is a series of knocks followed by a head slap.

It is likely that other benthic fishes are also using the seismic channel for communication. Other sculpins (Family Cottidae) such as the river bullhead (Cottus gobio) produce acoustic sounds coupled with a characteristic downward jerking of the head during courtship and agonistic interactions (Ladich, 1989). Additionally, gobies (Family Gobiidae) produce acoustic signals that are used in communication (e.g., Bathygobius soporator; Tavolga, 1958). These acoustic signals are produced during a similar head movement as seen during the production of seismic signals in sculpin.

\section{Acoustic Signals Produced at the Interface}

Rather than using the interface as a transmission channel, some animals appear to use the boundary between air and water to generate acoustic signals. These signals are produced by an animal striking the interface with a part of its body and then are propagated through the component media as a longitudinal pressure wave. The striking of the interface produces a sharp onset, broadband signal that might be used to communicate in noisy environments or possibly as a contact or ranging signal to convey information about the spatial location of the individual producing the signal.

The production of sounds at the air-water interface for communication has not been extensively studied. There are, however, examples in which specific behaviors have been suggested to generate sounds at the interface for communication. American alligators (Alligator mississippiensis) are described as performing a complex, stereotyped behavior in which individuals adopt a "head oblique, tail arched" (Vliet, 1989, p. 1021) body position that is immediately followed by vocalizations (bellows), vigorous tailwagging, jawclapping, and headslapping (Vliet, 1989). The jawclap and the headslap produce both aerial and underwater sounds, whereas the tailwag generates large amplitude surface waves. The precise function of this stereotyped behavior is not entirely clear, though it appears to indicate the location of the signaler and may play a role in the establishment and maintenance of dominance hierarchies (Vliet, 1989).

One of the most striking examples of surface generated acoustic signals is referred to as the aerial behaviors of cetaceans. Aerial behavior denotes a classification of behaviors in which whales and dolphins generate a large splash by striking the water's surface with some or all of their body (see Figure 1). Such behaviors include breaching and lobtailing and have been observed in many species (e.g., humpback whale, Megaptera novaeangliae, Whitehead, 1985; sperm whale, Physeter catodon, Waters \& Whitehead, 1990). Aerial behaviors are visible from a distance at sea and as such have attracted a great deal of thought on their possible function (Whitehead, 1985). Conjecture ranges from physiological hypotheses-removing parasites, stretching, or breathing during storms - to behavioral hypotheses-escaping from predators, stunning fish during feeding, making a visual signal of annoyance or arousal, playing, displaying of power, maintaining social cohesion, and communicating acoustically (reviewed in Whitehead, 1985). Whitehead (1985) suggested that aerial behaviors may have several different uses but considered acoustic communication to be one of the most likely functions.

One of the difficulties in determining the function of aerial behaviors is that studying these behaviors presents significant logistical challenges. For this reason, no experimental studies have been conducted, and all available evidence is entirely observational. Yet, close examination of the literature reveals several trends. First, aerial behaviors do generate acoustic signals. While recording whale vocalizations with hydrophones, researchers routinely detect loud sounds that are correlated with the performance of an aerial behavior. Würsig, Dorsey, Richardson, and Wells (1989) recorded low-frequency (less than $100 \mathrm{~Hz}$ and less than 600 $\mathrm{Hz}$ ), short duration (less than $1.5 \mathrm{~s}$ and less than $0.4 \mathrm{~s}$ ) sounds from the breaches and tail slaps, respectively, of bowhead whales ( $\mathrm{Ba}$ laena mysticetus). The intensity of these sounds ranged from 107 to $118 \mathrm{~dB}$ (re $1 \mathrm{~Pa}$ ) at a distance that was approximated as "several hundred meters” (Würsig et al., 1989, p. 31) from the source. Assuming simple spherical attenuation, a signal of this intensity could be detected above ambient background noise at a distance of many thousands of meters, although surface effects, sound shad- 


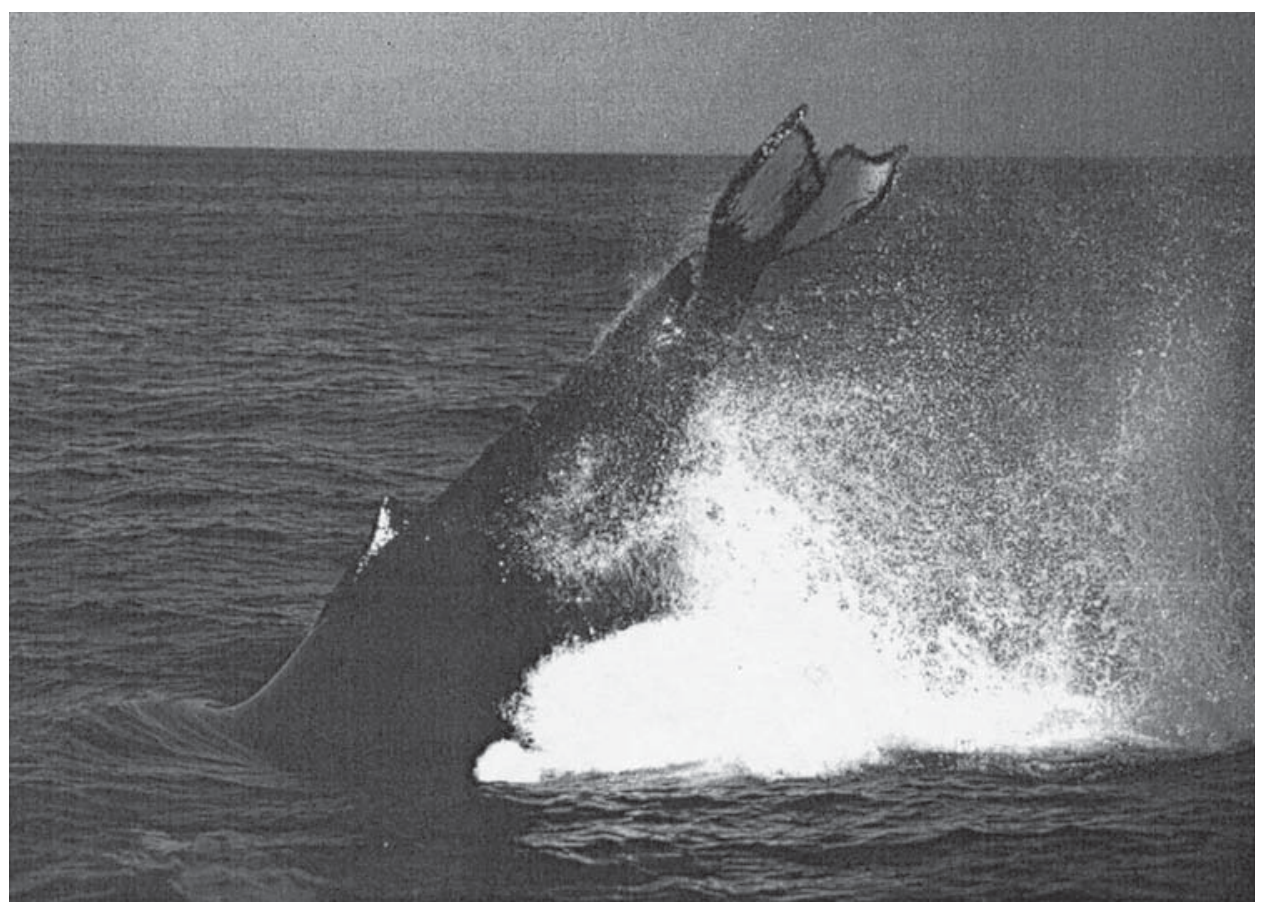

Figure 1. The performance of a tail breach aerial behavior by a humpback whale (Megaptera novaeanglia). Photo by Sean C. Lema.

ows, and differences in water density significantly alter the realized transmission properties. Similarly, Clark (1983) reported that the Southern right whale (Eubaleana australis) also generates sounds from aerial displays. Recording these sounds in a hydrophone array, Clark (1983) described the intensity of these sounds as comparable with the vocalizations of the right whale, although the sounds produced by aerial behaviors were distinctly different in composition. Southern right whale vocalizations were narrowband frequency with a slow onset and long duration, whereas the sounds produced by aerial behaviors were broadband with a sharp onset and short duration.

A second trend in the literature suggesting that aerial behaviors may be used for communication comes from the social context of these behaviors. Waters and Whitehead (1990) reported that breaching and tail slapping were frequently expressed by female sperm whales traveling in social groups and were only rarely expressed by the solitary males of the species. Waters and Whitehead also showed that the expression of aerial behaviors peaked in the late afternoon and that the frequency of these behaviors was positively correlated with an increase in the division and reassembly of social groups. In the humpback whale, Whitehead (1985) reported that aerial behaviors were common during the winter breeding season and infrequent during the months when whales spent the majority of their time feeding. The frequency of aerial behaviors by humpback whales peaked at midday, a time that correlated with an increase in social interactions (Helweg \& Herman, 1994).

Although the social context of aerial behaviors suggests a possible role in communication, aerial behaviors are expressed to a lesser extent in species not usually considered highly social (e.g., bowhead whale; Würsig et al., 1989). It is unclear, however, whether a researcher's interpretation of a social species of cetacean is biased by the perception of spatial relationships. It is evident from the literature that researchers are more likely to give credence to the idea that aerial behaviors serve a communication function if the whale performing the behavior is perceived as part of a social group. In cetaceans, social groups are classified by spatial proximity. Spatial proximity, however, is subject to our own human perception, and social groups of cetaceans have historically been defined by how many whales can be viewed at a single time from a single location. There is evidence, however, that cetaceans can acoustically communicate over long distances (Payne, 1995). If sounds produced by aerial behaviors propagate over a long distance, a socially cohesive group of whales may include individuals that are well out of the visual range of the researcher. For that reason, the perception of a social group may underestimate the social context of aerial behaviors in cetaceans.

\section{Discussion}

The physical properties of the air-water and water-substrate interfaces of the aquatic environment are very different than those to which we, as humans, are accustomed. Both interfaces are demarked by an abrupt change in molecular density that facilitates the production of communication signals. It is increasingly evident that animals physically disturb these interfaces to generate two types of signals: (a) a vibrational disturbance that propagates along the interface as a signal in a transmission channel or (b) a rapid mechanical displacement of the interface that produces an acoustic signal that travels through the component media. A variety of taxa exploit the air-water and water-substrate boundaries as a communication channel. These taxa commonly inhabit microhabitats on 
or near these boundaries. At the air-water interface, an animal can generate surface waves that propagate horizontally away from the source and may be detected by any individual that is on or near the water's surface. Similarly, benthic fish use the water-substrate interface as a channel for the transmission of vibrational signals. These exemplars rely on the disturbance of a boundary between media to generate a vibrational signal that travels along the interface.

There is also evidence that animals may strike the interface to produce an acoustic signal with the impact; the sound then propagates through the component media. In cetaceans, it is evident that aerial behaviors generate sounds (e.g., Clark, 1983). These behaviors may have several functions, and it is possible that the importance of aerial behaviors for communication varies with species, social situation, and age of the individual performing the display (Whitehead, 1985). It is clear, however, that the hypothesized functions of these behaviors have been shaped by our human perception of what constitutes a social group of cetaceans. If researchers record the performance of aerial behaviors by solitary individuals, then these researchers are led to hypothesize individual functions (i.e., removing parasites, stretching) for these behaviors. If researchers observe aerial behaviors by cetaceans in social groups, then the researchers hypothesize about the use of these behaviors for social purposes (i.e., communication, aggression). Yet, when researchers take the sensory world of the cetacean into account, it becomes possible that the individuals that researchers view as performing aerial behaviors in social isolation may actually be communicating over much greater distances (Payne, 1995).

The usefulness of signals produced at the boundaries may be as diverse as other modalities of communication. Water striders produce a variety of surface wave signals that differ in frequency and are used for both mate attraction and agonistic interactions (reviewed in Wilcox, 1995). In the Southern right whale, the slow onset, long duration, narrowband vocalizations contrast with the sharp onset, broadband sounds generated by the aerial behaviors of these animals (Clark, 1983). The sharp onset sounds from aerial behaviors may facilitate the localization of the sound source, similar to the use of sharp onset vocalizations for localization in other taxa (e.g., birds, Marler, 1957). Additionally, the signal characteristics of both the sounds generated from the aerial behaviors of cetaceans and the substrate vibrations of sculpins may be difficult to falsify. Such signals may serve as honest indicators of the body size or behavioral state of the signal producer and therefore provide specific information to the signal receiver.

As the above examples illustrate, each animal must be studied in the context of its own sensory and perceptual world (Von Uexküll, 1934/1957), and the signaling modalities that are the most obvious to humans may not be the modalities that are pertinent to the animal. Understanding the Umwelt of other animals stretches our human imaginations because many animals inhabit environments with physical properties that differ from that of humans. The interfaces between air and water or between water and substrate are prime examples of environments with unfamiliar physical properties. Compared with communication within a medium, researchers are just beginning to understand how animals use these interfaces for the production and detection of communication signals. Only by considering the animal in the context of its own environment and sensory world may researchers ever appreciate the diversity of ways that animals use these interfaces for communication.

\section{References}

Arnason, B. T., Hart, L. A., \& O’Connell-Rodwell, C. E. (2002). The properties of geophysical fields and their effects on elephants and other animals. Journal of Comparative Psychology, 116, 123-132.

Bleckmann, H. (1985). Discrimination between prey and non-prey wave signals in the fishing spider Dolomedes triton (Pisauridae). In K. Kalmring \& N. Elsner (Eds.), Acoustic and vibrational communication in insects (pp. 215-222). Berlin, Germany: Parey.

Bleckmann, H. (1994). Reception of hydrodynamic stimuli in aquatic and semiaquatic animals. Stuttgart, Germany: Fischer.

Clark, C. W. (1983). Acoustic communication and behavior of the Southern right whale (Eubaleana australis). In R. Payne (Ed.), AAAS Symposium on Communication and Behavior of Whales (Vol. 76, pp. 163198). Boulder, CO: Westview Press.

Helweg, D. A., \& Herman, L. M. (1994). Diurnal patterns of behaviour and group membership of humpback whales (Megaptera novaengliae) wintering in Hawaiian waters. Ethology, 98, 298-311.

Hoekstra, D., \& Janssen, J. (1985). Non-visual feeding behavior of the mottled sculpin, Cottus bairdi, in Lake Michigan. Environmental Biology of Fishes, 12, 111-117.

Janssen, J. (1990). Localization of substrate vibrations by the mottled sculpin (Cottus bairdi). Copeia, 1990, 349-355.

Kraus, W. F. (1989). Surface wave communication during courtship in the giant water bug, Abedus indentatus (Heteroptera: Belostomatidae). Journal of the Kansas Entomological Society, 62, 316-328.

Kühme, V. W. (1961). Verhaltensstudien am maulbrütenden (Betta anabatoides Bleeker) und am nestbauenden Kampffisch (B. splendens Regan) [Behavioral studies of a mouthbrooding (Betta anabatoides Bleeker) and a nestbuilding fighting fish (B. splendens Regan)]. Zeitschrift für Tierpsychologie, 18, 33-55.

Ladich, F. (1989). Sound production by the river bullhead, Cottus gobio L. (Cottidae, Teleostei). Journal of Fish Biology, 35, 531-538.

Marler, P. (1957). Specific distinctiveness in the communication signals of birds. Behaviour, 11, 13-39.

Payne, R. (1995). Appendix: A primer of ocean acoustics. In R. Payne (Ed.), Among whales (pp. 359-402). New York: Scribner.

Popper, A. N., \& Fay, R. R. (1993). Sound detection and processing by fish: Critical review and major research questions. Brain, Behavior, and Evolution, 41, 14-38.

Roland, C., \& Rover, J. S. (1983). Chemical and vibratory communication in the aquatic pisaurid spider Dolomedes triton. Journal of Arachnology, $11,77-85$.

Savage, T. (1963). Reproductive behavior of the mottled sculpin, Cottus bairdi Girard. Copeia, 1963, 317-325.

Seidel, B. (1999). Water-wave communication between territorial male Bombina variegata. Journal of Herpetology, 33, 457-462.

Tavolga, W. N. (1958). The significance of underwater sounds produced by males of the gobiid fish, Bathygobius soporator. Physiological Zoology, 31, 259-271.

Vliet, K. A. (1989). Social displays of the American alligator (Alligator mississippiensis). American Zoologist, 29, 1019-1031.

Von Uexküll, J. (1957). A stroll through the worlds of animals and men: A picture book of invisible worlds. In C. H. Schiller (Ed.), Instinctive behavior: The development of a modern concept (pp. 5-80). New York: International Universities Press. (Original work published 1934)

Walkowiak, W., \& Münz, H. (1985). The significance of water surfacewaves in the communication of fire-bellied toads. Naturwissenschaften, 72, 49-51.

Waters, S., \& Whitehead, H. (1990). Aerial behaviour in sperm whales. Canadian Journal of Zoology, 68, 2076-2082. 
Whang, A., \& Janssen, J. (1994). Sound production through the substrate during reproduction in the mottled sculpin, Cottus bairdi (Cottidae). Environmental Biology of Fishes, 40, 141-148.

Whitehead, H. (1985). Humpback whale breaching. In G. Pilleri (Ed.), Investigations on cetacea (Vol. 17, pp. 117-155). Bern, Switzerland: Brain Anatomy Institute.

Wilcox, R. S. (1972). Communication by surface waves: Mating behavior of a water strider (Gerridae). Journal of Comparative Physiology, 80, 255-266.

Wilcox, R. S. (1995). Ripple communication in aquatic and semiaquatic insects. Ecoscience, 2, 109-115.
Würsig, B., Dorsey, E. M., Richardson, W. J., \& Wells, R. S. (1989). Feeding, aerial and play behaviour of the bowhead whale, Balaena mysticetus, summering in the Beaufort Sea. Aquatic Mammals, 15, 27-37. 